International Journal of Instruction e-ISSN: 1308-1470 • www.e-iji.net

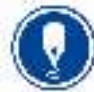

Article submission code: 20200413021756
Received: 13/04/2020

Revision: 22/09/2020
April 2021 • Vol.14, No.2

p-ISSN: 1694-609X

pp. $405-420$

Accepted: 15/10/2020

OnlineFirst: 26/01/2021

\title{
Information Seeking Behaviour and Personality Traits in Secondary- school Students
}

\section{Sukan Charoenkul}

Faculty of Industrial Educational and Technology, King Mongkut's University of Technology Thonburi, Bangkok, Thailand, sukan.crk@mail.kmutt.ac.th

\section{Sumalee Chanchalor}

Dr., Faculty of Industrial Educational and Technology, King Mongkut's University of Technology Thonburi, Bangkok, Thailand, sumalee.cha@kmutt.ac.th

Although personality traits can influence information-seeking behaviour (ISB), research on this relationship has received inadequate attention from researchers particularly at the secondary-school level. This study identified which of the individual Big Five Personality Traits (BFPT) had a significant effect on ISB and whether BFPT combined with either gender, programs of study, or achievement had an effect on ISB. Data collection involved a self-report survey with Thai secondary-school students $(\mathrm{n}=3400)$. Data analysis involved multiple regression, correlation, and two-way Anova. Results showed that of the five BFPT traits, Openness to experience followed by Conscientiousness had a significant effect on ISB. High levels of Extraversion, Agreeableness, Conscientiousness and Openness predicted higher achievement and ISB. Conscientiousness, Openness to experience, Extraversion, and Agreeableness were positively correlated with ISB. Neuroticism negatively correlated with ISB. Extraversion, Conscientiousness, Openness to experience, positively correlated with academic achievement. Females with any of the five BFPT had higher ISB mean scores than males. Students in Mathematics-Science program with any BFPT had higher ISB mean scores than those in Language Arts-Social Studies program.

Keywords: information seeking behaviour, big five personality traits, secondary school, academic achievement, gender

\section{INTRODUCTION}

Long before the advent of the Internet, researchers were already investigating information-seeking behaviours. Wilson (1981) identified such behaviours as arising from satisfaction of physiological, affective (e.g., security or achievement) and cognitive needs. Wilson argued that these needs were so intense, that references to information seeking should be, instead called, "information-seeking towards the satisfaction of needs" (Wilson, 1981, p.6). Wilson further argued that we must understand why users

Citation: Charoenkul, S., \& Chanchalor, S. (2021). Information Seeking Behaviour and Personality Traits in Secondary-school Students. International Journal of Instruction, 14(2), 405-420. https://doi.org/10.29333/iji.2021.14223a 
seek information, for what purposes and what the user actually does with the information. The relationship between affective needs and information seeking behaviours can be explained in terms of examples such as the need to seek information to gain approval from others by showing that one is "better informed and, therefore, in some sense superior" (p. 7). Adoption of this perspective on information seeking demands that the phenomenon be conceptualized and investigated from what Wilson refers to as a "wider, holistic view of the information user" who seeks information not merely for cognitive purposes but to satisfy affective needs within social settings (p. 9). Wilson's perspective on information-seeking behaviours (ISB) provides support for investigations of this phenomenon in relation to personality traits. Researchers have identified relationships between personality traits and ISB (see Kim et al., 2014) as well as personality traits and academic achievement (Heinström et al., 2014). Halder et al. (2010) also found that such traits can influence ISB. Ozowa and Aba (2017) concluded that traits "play essential roles" in ISB in academic settings and can even determine individual student differences. In general, as Volodina et al. (2019) explained, personality traits and basic psychological needs are related.

\section{Personality and ISB}

Personality is a term used to denote underlying traits that influence individual behaviour, cognition and affect (McGeown et al., 2014). It plays a role in academic success (Poropat, 2009), can shape academic achievement (Köseoğlu, 2016), and predict it (Rimfeld, 2016). It can also affect learning styles (Nyarko et al., 2016) as well as intellectual skills development (Rammstedt, 2016). Likewise, education and learning opportunities can play a role in developing and shaping personality (Karatas, 2015). The Five-Factor Model known as Big Five Personality Traits (BFPT) was first identified by McCrae and Costa (1988). Personality was explained in this model along five central dimensions: Openness to experience, Conscientiousness, Extraversion, Agreeableness, and Neuroticism (McCrae \& Costa, 1988).

Halder et al. (2010) found that "the five personality traits are significantly correlated to all the dimensions of information seeking behavior" of higher educational students. Halder et al. (2010) found that traits can influence attitudes and behaviours in contexts of information-seeking and can interact with contextual factors to motivate certain information seeking behaviours as well as use of information (Halder et al., 2010). Zhitomirsky-Geffet and Blau (2017) found a positive relationship between information seeking and Extraversion. The trait of Extraversion includes characteristics such as sociability, talkativeness and assertiveness particularly in social situations (Cherry, 2017). Extraversion refers to the tendency to be fun-loving, adopt leadership positions (Kwon \& Song, 2011) be gregarious and seek excitement (Suldo et al., 2014). Introverts, on the other hand, display a tendency to be more reserved in social settings (Cherry, 2017) and are inclined to be less talkative, more reserved, shy (Costa and McCrae, 1992), withdrawn and independent (Heinström, 2003).

Al-Samarraie et al. (2016) found a correlation between personality traits and knowledge acquisition. Their results showed that high Conscientiousness resulted in faster information-seeking tasks. Conscientiousness includes traits such as thoughtfulness and 
good impulse control such that those with high levels of the trait tend to be organized and mindful of details (Cherry, 2017), competent, responsible, thorough (Costa and McCrae, 1992). In particular, these individuals are goal-directed which makes them better able to achieve in contexts of learning (Heinström, 2003). Not surprisingly, this trait has been correlated with academic success (Grass et al., 2017). In general, individuals who are not Conscientiousness are more inclined towards impulsiveness and carelessness (Kwon and Song, 2011).

Heinström (2005) identified interactions between personality traits and approaches to study that affect information-seeking patterns. Heinström's results showed that low Openness to experience and low Conscientiousness were related to fast surfing. Extraversion, Openness to experience, and competitiveness were related to broad scanning. Individuals with the trait of Openness to experience display imagination, insight, a broad range of interests, creativity (Cherry, 2017) and, urge for experiences (Halder et al., 2010), divergent thinking, and intellectual curiosity (Costa \& McCrae, 1992). Those low in this trait may have difficulty with abstract thinking (Cherry, 2017) and prefer familiarity (Howard \& Howard, 1995). Agreeableness involves prosocial behaviours such as tendency towards cooperation versus competitiveness (Cherry, 2017). Agreeable people may demonstrate interpersonal tendencies of altruism, kindness, sympathy (Costa and McCrae, 1992) and compassion (Kwon and Song, 2011). The opposite of A would include such traits as indifference, self-centeredness, and jealousy (Howard \& Howard, 1995), critical and impatient (Kwon and Song, 2011). Those with this trait tend to use a variety of information-searching techniques (Ahmed et al., 2019) and may be motivated to search for information (Costa \& McCrae, 1992). Schmidt and Wolff (2016) found that Agreeableness was positively correlated with use of different search strategies.

Neuroticism relates to affect and emotional control (Heinström, 2003). Individuals with the trait of Neuroticism may display mood swings, anxiety, irritability, emotional instability (Cherry, 2017), negative affectivity, nervousness (McCrae \& John, 1992), depression and self-consciousness (Suldo et al., 2014). Those with higher levels of Neuroticism are more likely to experience negative emotions such as worry and sadness and may be more inclined to be negatively affected by their environment (Heinström, 2003). Individuals who are low in this trait may show more emotional stability and resilience (Cherry, 2017). Those with this trait may be unmotivated to seek information (Ahmed et al., 2019). In general, Neuroticism tends to correlate negatively with ISB (Heinström, 2003).

\section{Rationale and Purpose}

Researchers have identified the need to research BFPT and ISB. For example, Heinström (2005) argued, it is important to identify how personality traits affect ISB. Yet, although personality can influence ISB, it has received inadequate attention from researchers and, particularly in relation to the "most modern personality theory to date," i.e., the BFPT (Halder et al., 2010). Similarly, Al-Samarraie et al. (2016) noted the lack of knowledge about how personality traits influence ISB. Tidwell and Sias (2005) argued that personality traits have received inadequate attention in research on 
information-seeking. There have been some indirect links made in the literature between achievement, personality traits and ISB. Heinström et al. (2014) explained that research has linked achievement with personality traits such as conscientiousness (e.g., Poropat, 2009) while conscientiousness has been linked with learning-related information behaviour. Heinström et al. argued, however, that there is a lack of understanding of the relationship between personality and learning-related information behaviour. In addition, while there has been research conducted on ISB and BFPT at the postsecondary level, there has been considerably less attention to this construct at the secondary level. In the past, secondary students may have been less engaged in independent information seeking. However, increased access to the Internet is resulting in more students seeking information. Gender and personality traits is another area that needs examination in relation to ISB (Kwon \& Song, 2011). In relation to gender and information seeking, Zhitomirsky-Geffet and Blau (2017) found significant differences between men and women in terms of their ISB with smart phones. The authors found that men relied more on functional/cognitive information-seeking than women.

It is with these gaps in mind that the study reported on in this paper was designed. The study's investigation was driven by the following questions:

1 Which of the individual five BFPT has a significant effect on ISB?

2 What is the relationship (if any) between BFPT, ISB and educational achievement?

3 Does the interaction of BFPT and gender significantly affect ISB?

4 Does the interaction of BFPT and programs of study (Mathematics-Science vs. Language Arts-Social Studies) significantly affect ISB?

\section{Conceptual Framework: Information-seeking}

Information seeking (IS) involves purposeful behaviour designed to satisfy a particular goal (Wilson, 2000) and gathering information to reduce uncertainty (Tidwell \& Sias, 2005). Information seeking behaviour (ISB) refers to the activities in which individuals engage and may include such processes as searching, using and transferring. Information seeking and ISB can be distinguished from information literacy in that the latter refers to abilities that seekers can rely on to find, evaluate and use information (American Library Association, 2000). IS can also be distinguished from information competency which involves being competent in the search for and use of information (Kwon \& Song, 2011, p.88). Individuals consciously seek information because they recognize an inadequacy in their knowledge to satisfy a need (Marchionini, 1997) or search for meaning to enrich knowledge. For example, students require information to fulfil their academic needs (Nadzir et al., 2015). IS is a part of the more general phenomenon of information behaviour which may be "unintentional," "passive" or purposive (p. 5). It involves cognitive processing and interpretation (Zhu et al., 2011) as well as behaviours such as acquiring knowledge, understanding and interpreting concepts and can even involve socialization (Marchionini, 2006). Learning-related information behaviour involves seeking information for purposes of learning and may be referred to in some contexts as inquiry learning (Heinström et al., 2014). As Zhu et al. (2011) explained, IS "has always been interwoven with learning" (p. 2478). 
Ikoja-Odongo and Mostert, (2006) argued that IS can follow unique behaviours depending on the seekers' circumstances and may include "starting, chaining, browsing, differentiating, monitoring, extracting, verifying, and ending" (p.149-150). Timmers and Glas (2010) identified processes including first defining the problems, identifying sources, using search strategies, and evaluating the information. Nadzir and Salim (2013) argued that IS should start with identifying what information is needed, followed by selection of sources and then finding the information "by using selected strategies" (p.168). Other perspectives simply refer to a process of initial perceptions of a gap in terms of one's need for knowledge for an issue or problem - a process that ends "when that perception no longer exists"” (Moore, 2016, p.140). Ellis (1989) refers to starting, chaining, browsing, differentiating, monitoring, and extracting. IS may take place using manual systems such as a newspaper or by means of a computer (Wilson, 2000). More recently, the Internet has emerged as students' main source for information (Aharony \& Gur, 2017). Figure 1 provides an overview of information seeking and information seeking behaviours.

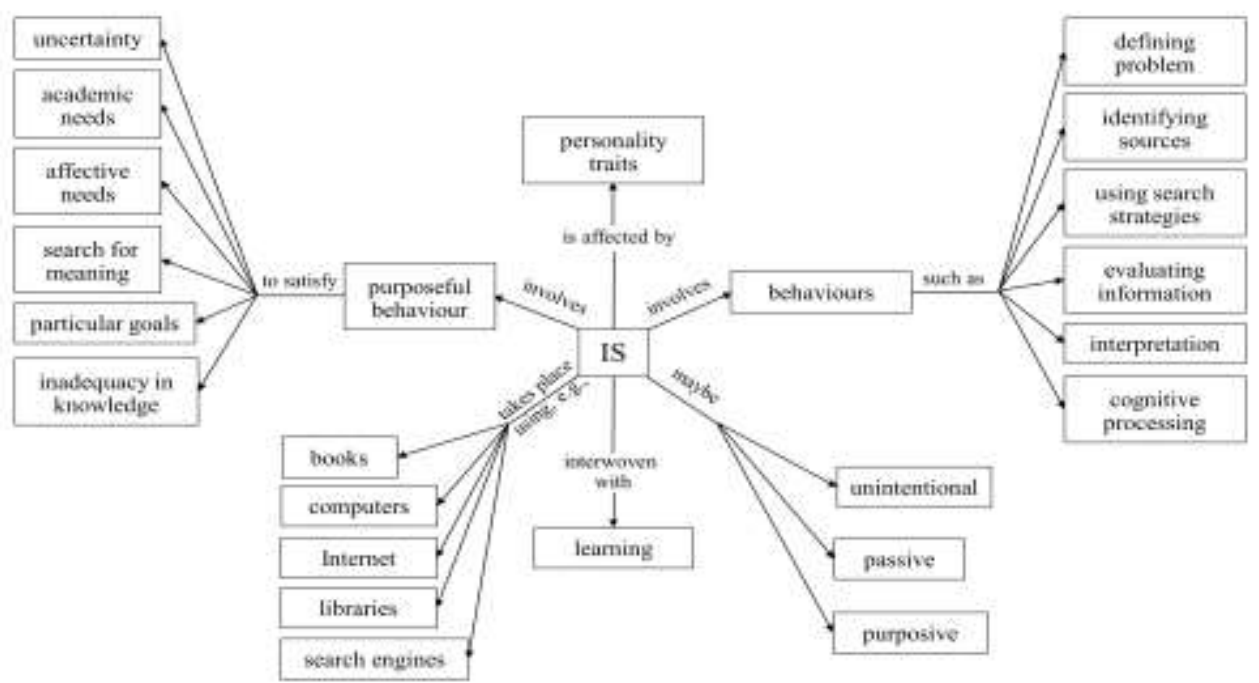

Figure 1

Information-Seeking behaviour

\section{ISB AND BFPT IN EDUCATION}

The focus of this study was on secondary-school students. However, the review uncovered only one study (Heinström et al., 2014) at this level. Heinström et al. examined the effect of BFPT combined with study approach on 219 Finnish senior, secondary-school students' learning-related information behaviour. Data were collected using three questionnaires and analyzed by regression. The authors found that approaches to studying had a stronger influence than personality traits at the task performance and task completion stage. The individual variables of personality and 
approach to studying had a stronger influence on students' behaviour than did their grades. Personality traits had more impact at the task construction phase whereas study approaches had more impact on task performance and task completion. In general, the authors found that personality traits had the most influence when students were actually using information. The study reported on in this paper also focused on BFPT and secondary-school students. However, Heinström et al. (2014) focused on information behaviour whereas this study focused on information-seeking behaviour. Also, this study is broader in scope and considers the variable of gender. Also, the study reported in this paper considers which traits are most likely to affect ISB in secondary-school students. There have been numerous studies conducted at the post-secondary level.

Some studies have limited the scope to identifying the relationship between BFPT and ISB (e.g., Al-Samarraie et al., 2016: Song \& Kwon, 2012; Halder et al., 2010; Heinström, 2005; Ozowa \& Aba, 2017). Al-Samarraie et al. (2016) examined the impact of BFPT on online information seeking by examining eye-movement behaviour. They found that people "high in conscientiousness performed fastest in most informationseeking tasks, followed by those high in agreeableness and extraversion." Song and Kwon (2012) investigated the relationship between BFPT and information competency comparing Korean and American cultures. The study revealed that "conscientiousness and openness to experience significantly predicted information competency in both Korean and American students. However, the influence of extraversion was significant only for American students." Kwon and Song (2011) identified an effect on information competency for the three traits of conscientiousness, openness to experience, and extroversion. The authors also found that information competency was affected by gender-specific personality traits. Extraversion was a male-specific trait whereas openness to experience was a female-specific trait. For both males and females, conscientiousness was "the most consistent and robust determinant of information competency." Al-Samarraie et al. (2016) also found a positive relationship between conscientiousness and information-seeking tasks. Kim et al. (2014) found significant differences between frequency and purpose of information seeking on one hand, and on the other, gender, class level, academic discipline, and BFPT. Aharony and Gur (2017) concluded that openness to experience and curiosity combined with deep learning strategies, self-efficacy in computer use and computer mastery affected students' level of information literacy (p. 1). Ahmed et al.'s (2019) study focused on differences in students' personality traits in relation to their information needs and seeking behaviour. The results revealed that extraverted students showed more concern about their information needs while conscientious students were more "seekers of information" (p. 125).

\section{METHOD}

\section{Participants}

The population in this study included 1,249,373 upper secondary-school students in Thailand (Thai Bureau of Information and Communication Technology, 2018). According to Yamane's (1973) formula, when the population exceeds 100,000, a sample should be approximately 1,100 . Combined with stratified random sampling technique, 
the sample drawn from this population was 3,400 students, aged from 15 to 18 . These included 938 males and 2,462 females. In terms of program, 2,165 were enrolled in Mathematics-Science and 1,248 were enrolled in Language Arts-Social Studies.

\section{Measures}

To measure the BFPT, various instruments have been developed. The most extensive one is the 240-item NEO Personality Inventory (NEO-PI) by Costa and McCrae (1992) and revised version (NEO-PI-R) measuring six specific features in each dimension and taking about 45 minutes to complete. Shorter, consecutive instruments have been developed to reduce the time required to finish the questionnaire. There is also a 60-item NEO Five-Factor Inventory (NEO-FFI; Costa \& McCrae, 1992). While these instruments have been widely used in other studies, they were not adopted for use in this study because of their length. Instead, the study used a well-established Big-Five Inventory (BFI) by John and Srivastava (1999) which is limited to 44-items. The BFI has been used in many studies (e.g., Rammstedt \& John, 2007). Respondents are asked to provide agreement or not to the prompt "I see myself as someone who...". They could respond using a 5-Likert scale from 1 (disagree strongly) to 5 (agree strongly). Items for each facet are presented in both positive and negative terms. The negative items are reverse coded. There are eight items for Extraversion (e.g., Is talkative: Is reserved), nine items for Agreeableness (e.g., Is sometimes rude to others; Likes to cooperate with others), nine items for Conscientiousness (e.g., Does things efficiently; Tends to be lazy), eight items for Neuroticism (e.g., Worries a lot; Is relaxed, handles stress well), and 10 items for Openness to experience (e.g., Is inventive, Prefers work that is routine).

ISB was measured using the information-seeking behaviour scale by Timmers and Glas (2010). The scale includes 46 items asking how often participants engaged in a particular behaviour when searching for information to complete study assignments. Like the BFI, this instrument uses a 5-point Likert scale as follows: 5 (always); 4 (usually); 3 (sometimes); 2 (occasionally); and 1 (hardly ever or never). Respondents are asked about what they do when they are searching for information to complete study assignments. There are 11 items for using sources (e.g., I consult Google), 13 items for applying search strategies (e.g., I use the option 'advanced search'), 15 items for evaluating information (e.g., I use the top list results), and five items for referring to information (e.g., and write a report, I use reference standards to refer to sources used). The questionnaires were piloted with 90 upper secondary school students to examine reliability. Cronbach's alpha were .864 and .843 for the BFI and ISB scales respectively.

\section{Procedures}

The principal investigator (PI) first contacted by telephone, teachers in 42 public schools and two private schools to request permission to conduct the study. This number was chosen using stratified random sampling. In cases where teachers within a school agreed to distribute the survey, the researcher then mailed copies to school principals. A total of 4,200 surveys were mailed to schools. Postage was provided for the return of the questionnaire. Of these 4,200, 3,413 were returned accounting for an $81 \%$ return rate. 
Thirteen had missing information leaving a total of 3,400. Ethics' procedures conformed to those of the university in which the PI was a Ph.D. candidate. Completion of the questionnaire meant that students provided their voluntary consent. They were informed of the confidential nature of the aggregated results and that their participation or lack thereof had no bearing on their school grades.

\section{Data Analysis}

For research questions 1-2, multiple regression and Pearson's correlation analysis were used to examine the impact of each BFPT on ISB and to investigate the relationship between BFPT, ISB and achievement, respectively. For research question 2, Pearson's correlation analysis was used to investigate the relationship between BFPT, ISB and achievement. For research question 3-4, two-way ANOVA was used. Students' ISB served as the dependent variable with BFPT and other variables (e.g., gender \& programs of study) as the independent variables. A two-way ANOVA was used because there were two independent variables (Huck, 2012) and to analyse the effects as well as the interaction "between a continuous variable and two categorical variables" (Winocur et al., 2010, p.3).

\section{FINDINGS}

The first research question asked which of the individual five BFPT has a significant effect on ISB. Considering individual traits, Openness to experience (O) had the most significant effect on ISB followed by Conscientiousness (C). Table 1 shows the regression models for ISB by effective BFPT and overall BFPT. The results show that significant personality traits positively linked to ISB included BFPT $(\mathrm{t}=8.44, p<.01)$, Openness to experience $(\mathrm{t}=7.73, p<.01)$, and Conscientiousness $(\mathrm{t}=4.76, p<.01)$. The equation explaining ISB with $\mathrm{R}^{2}=.20$ (the model predicted $20 \%$ of the variance) was ISB $=52.207+.435 \mathrm{BFPT}+.712 \mathrm{O}+.463 \mathrm{C}$. This means that individuals who are more open to experience and conscientious will be more effective in their information seeking behaviours.

Table 1

Models of ISB by BFPT

\begin{tabular}{lccccc}
\hline Variable & $\mathrm{R}$ & $\mathrm{R}^{2}$ & $\beta$ & $\mathrm{t}$ & $p$ \\
\hline BFPT & .45 & .20 & .25 & 8.44 & .00 \\
\hline Openness & & & .18 & 7.73 & .00 \\
\hline Conscientiousness & & & .10 & 4.76 & .00 \\
\hline
\end{tabular}

Regarding research question 2: What is the relationship (if any) between BFPT, ISB and achievement $(\mathrm{ACH})$, there were statistically significant positive and moderate correlations between ISB and two traits and BFPT, i.e., Conscientiousness (C) (r(3413) $=.312, \mathrm{p}<.01)$, Openness to experience $(\mathrm{O})(\mathrm{r}(3413)=.373, \mathrm{p}<.01)$, and Big Five $(\mathrm{r}(3413)=.436, \mathrm{p}<.01)$ while two traits had significant positive and weak correlations, i.e., Extraversion $(\mathrm{E})(\mathrm{r}(3413)=.257, \mathrm{p}<.01)$, Agreeableness $(\mathrm{A})(\mathrm{r}(3413)=.199, \mathrm{p}<$ $.01)$. However, there was a significant negative and weak correlation between ISB and Neuroticism $(\mathrm{N})(\mathrm{r}(3413)=-.060, \mathrm{p}<.01)$. Furthermore, factors significantly, positively correlated with achievement included $\mathrm{E}(\mathrm{r}(3238)=.08, \mathrm{p}<.01), \mathrm{C}(\mathrm{r}(3238)=.14, \mathrm{p}<$ 
$.01), \mathrm{O}(\mathrm{r}(3238)=.16, \mathrm{p}<.01)$, BFPT $(\mathrm{r}(3238)=.16, \mathrm{p}<.01)$, using source (Source) $(\mathrm{r}(3238)=.17, \mathrm{p}<.01)$, applying search strategies $($ Strat $)(\mathrm{r}(3238)=.29, \mathrm{p}<.01)$, evaluating information (Eval) $(\mathrm{r}(3238)=.21, \mathrm{p}<.01)$, referring to information (Ref) $(\mathrm{r}(3238)=.12, \mathrm{p}<.01)$, and ISB $(\mathrm{r}(3238)=.26, \mathrm{p}<.01)$. Figure 2 shows the correlation between BFPT, ISB, and achievement.

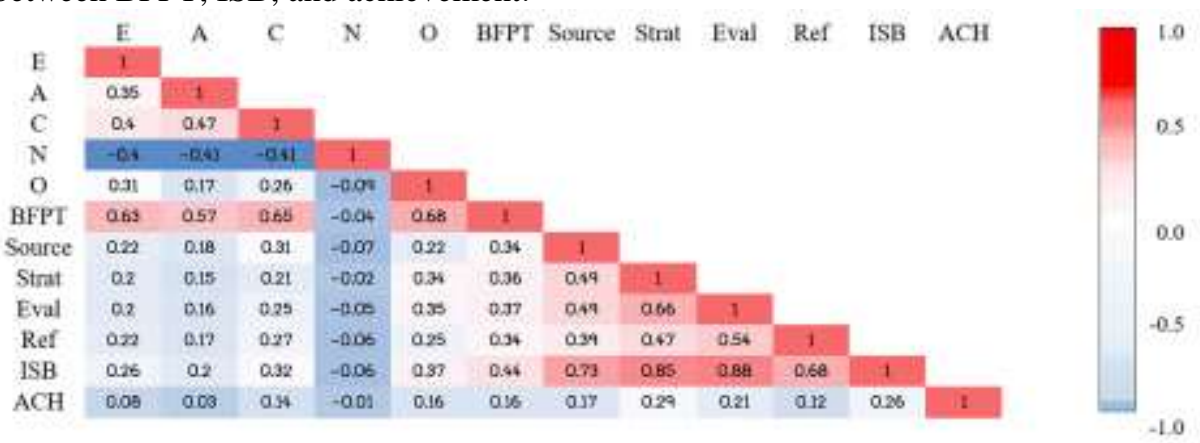

Figure 2

Correlation between BFPT, ISB, and achievement (Pearson correlation)

Research question 3 asked if the interaction of BFPT and gender significantly affected ISB? The interaction of BFPT and gender (BFPT*gender) had a significant effect on ISB $(p<.05)$. In other words, ISB differed with the BFPT of male/female $(F=5.92, p<$ .02). The two-way ANOVA also showed significant main effects on ISB; i.e. ISB for different BFPT and for both genders $(\mathrm{F}=414.34, \mathrm{p}<.00$ and $\mathrm{F}=14.02, \mathrm{p}<.00$, respectively).

Table 2

Summary of the two-way ANOVA of the variance for the variables of BFPT and gender and their interaction

\begin{tabular}{llllll}
\hline Source & SS & df & MS & F & $p$ \\
\hline BFPT & 141063.30 & 1 & 141063.30 & 414.34 & .00 \\
\hline Gender & 9548.79 & 2 & 4774.40 & 14.02 & .00 \\
\hline BFPT *Gender & 2015.94 & 1 & 2015.94 & 5.92 & .02 \\
\hline Error & 1155827.16 & 3395 & 340.45 & & \\
\hline Total & 78397884.00 & 3400 & & & \\
\hline Note: R squared $=.13($ Adjusted & R squared $=.13)$ &
\end{tabular}

Note: $\mathrm{R}$ squared $=.13$ (Adjusted R squared $=.13$ )

The Post hoc test, (see Figure 3) between male and female students for low and high BFPT, differentiating by the mean of BFPT showed that females with both low and high BFPT had higher scores in ISB than males. Moreover, both genders of students with low BFPT had lower scores in ISB than students with high BFPT. It can be implied from two-way ANOVA results that how well students do in ISB can be explained not only by BFPT but also by gender. 


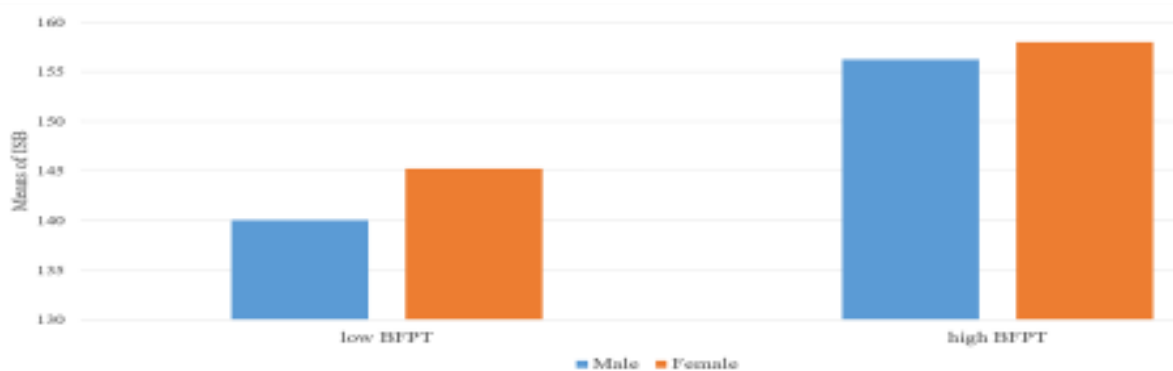

Figure 3

Bar chart indicating means of ISB as the effect of BFPT and gender

Regarding research question 4, results revealed that the interaction of BFPT and programs of study (BFPT*Programs of study) had a significant effect on ISB $(p<.01)$ as shown in Table 3. The two-way ANOVA also showed significant main effects on ISB; i.e., ISB for different BFPT and for different programs of study $(\mathrm{F}=466.09, \mathrm{p}<.00$ and $\mathrm{F}=37.07, \mathrm{p}<.00$, respectively).

Table 3

Summary of the two-way ANOVA of the variance for the variables of BFPT and programs of study and their interaction

\begin{tabular}{llllll} 
Source & SS & df & MS & F & $p$ \\
\hline BFPT & 157997.26 & 1 & 157997.26 & 466.09 & .00 \\
\hline Programs of study & 12566.83 & 1 & 12566.83 & 37.07 & .00 \\
\hline BFPT* Programs of study & 2036.07 & 1 & 2036.07 & 6.01 & .01 \\
\hline Error & 1155594.48 & 3409 & 338.98 & & \\
\hline
\end{tabular}

Note: $\mathrm{R}$ squared $=.14$ (Adjusted R squared $=.13$ )

The Post hoc test, shown as bar chart in Figure 4, between students in Mathematics (Math)-Science (Sci) program and Language Arts (Lang)-Social Studies (Soc) program for low and high BFPT showed that students in Math-Sci program with both low and high BFPT had higher means of ISB than those in Lang-Soc program. In addition, students with low BFPT in both programs of study had lower ISB means than those with high BFPT.

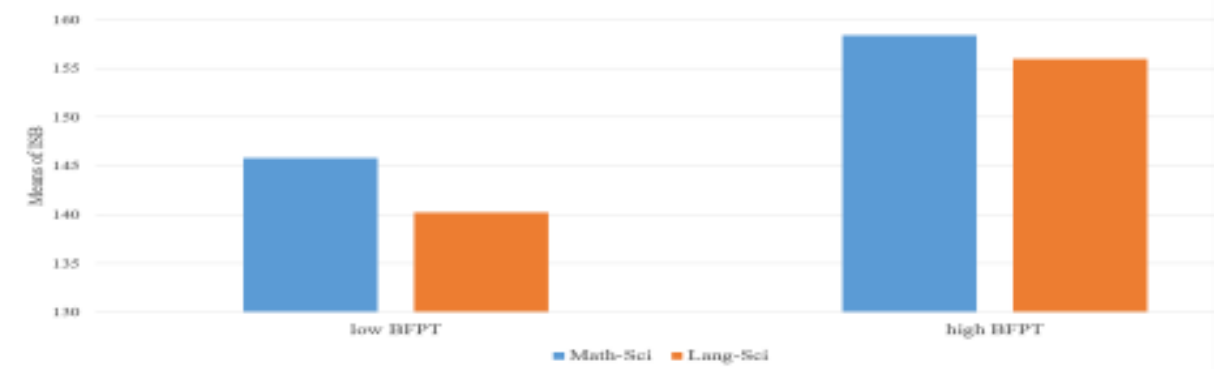

Figure 4

Bar chart indicating means of ISB as the effect of BFPT and programs of study 


\section{DISCUSSION}

Although personality traits can influence ISB, research on this relationship has received inadequate attention from researchers. This study identified which of the individual Big Five Personality Traits had a significant effect on ISB and whether BFPT combined with either gender, program of study, or achievement had an effect on ISB. The results of the study's four research questions are presented in figure 5. The figure highlights the positive ( + correlated) and negative (- correlated) correlations as well as effects and interactions.

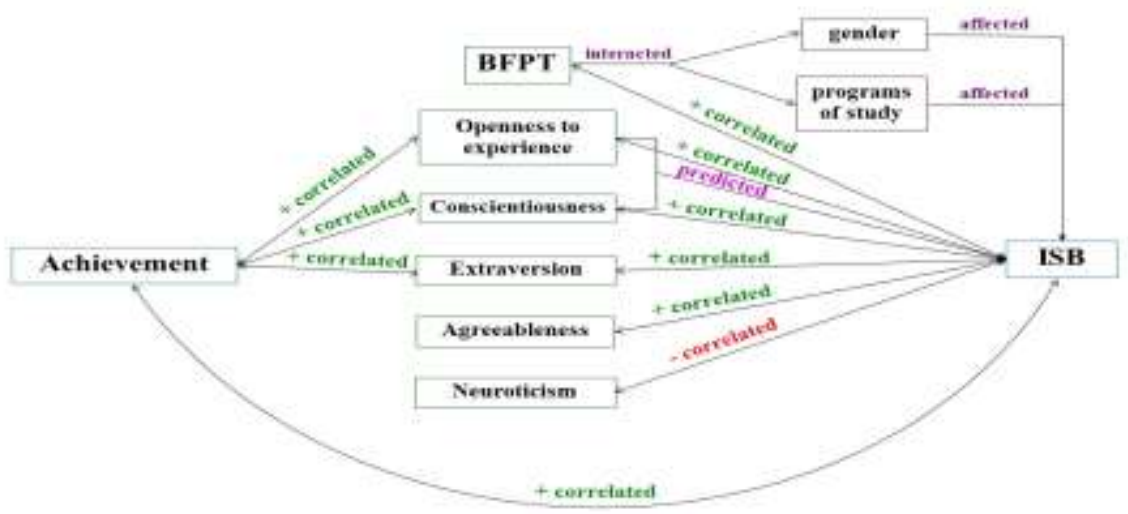

Figure 5

Summary of results

Regarding the first research question: which of the individual five BFPT has a significant effect on ISB, results showed that Openness to experience and Conscientiousness, were significantly positively linked to ISB with the model predicting $20 \%$ of the variance. This means that individuals who are more open to experience and conscientious will be more effective in their information seeking behaviours. These results are confirmed by studies conducted at the post-secondary level such as Aharony and Gur's (2017) study. These authors found that higher openness and curiosity resulted in higher levels of information literacy. Kwon and Song's (2011) post-secondary study found that extroversion, openness, and conscientiousness predicted information evaluation and information competency but only openness, and conscientiousness predicted information search strategies. This study focused on information seeking behaviours as one construct. The authors did not, like Kwon and Song, break down ISB into multiple components and subsequently identify which traits predicted which components. Given that openness to experience and conscientiousness were positively associated with ISB and information competency and literacy suggests a commonality between secondary and post-secondary students in terms of traits and ISB.

The second research question asked: What is the relationship (if any) between BFPT, ISB and educational achievement? Results showed that Openness to experience, Conscientiousness, and overall BFPT had a significantly positive and moderate 
correlation with ISB. There was a weak correlation between each of Extraversion and Agreeableness and ISB. However, ISB and Neuroticism were significantly negatively correlated. Factors significantly and positively correlated with achievement included Extraversion, Conscientiousness, Openness, overall BFPT, using sources, applying search strategies, evaluating information, referring to information, and overall ISB. Aharony and Gur (2017) found that openness to experience was positively correlated with levels of information literacy. However, that correlation was indirect in the sense that being open meant that students were more likely to be deep learners and have higher self-efficacy related to using computers, therefore they had higher information literacy levels. Ahmed et al. (2019) found that extraverts were more concerned about information. Halder et al. (2010) found that "Information seeking behaviour as a whole was positively correlated with extraversion, openness and conscientiousness and negatively correlated with neuroticism." Halder et al. and Ahmed et al. focused on postsecondary students. Heinström's secondary-school study (2003) revealed that difficulties identifying relevance of information was correlated with low conscientiousness, low agreeableness, high neuroticism and low openness.

The third research question asked whether the interaction of BFPT and gender significantly affected ISB? The interaction of BFPT and gender (BFPT*gender) had a significant effect on ISB. The Post hoc test showed that females with both low and high BFPT had higher scores in ISB than males. Moreover, both genders of students with low BFPT had lower scores in ISB than students with high BFPT. These results are consistent with those of Kwon and Song (2011) who identified significant gender differences in that female students showed higher information competency. Halder et al. (2010) also found ssignificant differences in ISB with females scoring high on all the domains of information search except for diversity. Regarding the fourth research question regarding the interaction of BFPT and programs of study results revealed the interaction of BFPT and programs of study had a significant effect on ISB. In addition, students in Math-Sci program with low and high BFPT had higher ISB means than students in Lang-Soc program. Whitmire's (2002) study of undergraduate students identified statistically significant differences in ISB in favour of those in life science who engaged more in information-seeking than those in the hard sciences.

\section{CONCLUSION}

Information seeking behaviour is an important topic particularly in the current context of ubiquitous and pervasive access to online tools for accessing, sharing and disseminating information. In the past, in teacher-centred classrooms, ISB might have been less important. This is because the information with which students dealt largely came from textbooks, didactic materials and information and knowledge disseminated by the teacher. Currently, access to the Internet combined with the prevalence of technology means that students are accessing and sharing information independently. Yet it is unclear what if any skills or behaviours they are being taught in order to ensure that their ISB meets its intended learning-related goals. Students may have strong digital information and communication skills in one area and yet, as Aharony and Gur (2017) observed, they may need to learn how to evaluate the information they access. Smith et 
al. (2013) concluded that the high-school students in their study experienced problems not only in identifying their information needs but in meeting those needs. Furi and PetrBalog's (2016) study with post-secondary students revealed that students' information seeking skills were "poor."

This study has provided some insights that can help build a better understanding of how to improve students' ISB. The study, first and foremost, confirmed the link between ISB and BFPT in secondary students. The study also made evident that ISB is not merely a cognitive skill that can be taught. Instead, it should be conceptualized broadly as being related to satisfaction of needs that are personal and varied. It also needs to be conceptualized as something very holistic that is bound and affected by personality. That conceptualization has implications for teacher education and professional development. It suggests that a one-size-fits-all approach to improving students' ISB is likely to be inadequate. This is because such behaviour varies from one personality type to the other and depends on gender and on program of study. In terms of implications for pre- or in-service education of teachers, it would be relevant for them to learn how to better assess the personalities of students early on, at the start of the school year. Equipped with that knowledge, teachers can encourage group activities and projects in which there is a mix of personality types. According to this approach, groups might include a combination of males and females, extraverted and introverted, students who are and who are not open to experiences or who are or are not conscientious, etc. Such groups might be also be heterogeneously composed of a mix of backgrounds, for example, from both Math-Science and Language Arts-Social Studies. When learning materials, either print or digitally based are being created, they should be designed to accommodate the combination of students' different information seeking behaviours based on aspects of personality. For example, students inclined towards neuroticism might benefit from more controlled searches within smaller databases.

In terms of limitations, results should be considered in relation to the study's limitations. This study was limited to one country only -Thailand. The other limitation relates to data collection which was by self-report only and was not triangulated with observation and interviews. Individuals may perceive their personality traits differently than they actually demonstrate them in real contexts. The study focused specifically on ISB and did not consider other related terms such as information literacy. These limitations may inform future research that can build on results from this paper.

\section{REFERENCES}

Aharony, N., \& Gur, H. (2017). The relationships between personality, perceptual, cognitive and technological variables and students' level of information literacy. Journal of Librarianship and Information Science, 1-18.

Ahmed, S. \& Rehman, F., \& Sheikh, A. (2019). Impact of personality traits on information needs and seeking behavior of LIS students in Pakistan. Information Discovery and Delivery, 47(3), 125-134.

Al-Samarraie, H., Eldenfria, A., \& Dawoud, H. (2016). The impact of personality traits on users' information-seeking behavior. Information Processing \& Management, 1-11. 
Cherry, K. (2017). The big five personality traits: 5 major factors of personality. Retrieved from https://www.verywell.com/the-big-five-personality-dimensions2795422.

Costa, P.T.Jr. \& McCrae, R.R. (1992). The Five-Factor model of personality and its relevance to personality disorders. Journal of Personality Disorders, 6(4), 343-359.

Ellis, D. (1989). A behavioural approach to information retrieval system design. Journal of Documentation, 45(3), 171-122. https://doi.org/10.1108/eb026843.

Furi, I. \& Petr Balog, K. (2016). Information seeking behaviour in the digital environment: information science vs. non-information science students. Revija Knjižnica. 60, 61-82.

Grass, J., Strobel, A., \& Strobel, A. (2017). Cognitive investments in academic success: The role of need for cognition at university. Frontiers in Psychology, 8, 790.

Halder, S., Roy, A., \& Chakraborty, P.K. (2010). The influence of personality traits on information seeking behavior of students. Malaysian Journal of Library \& Information Science, 15(1), 41-53.

Heinström, J. (2003). Five personality dimensions and their influence on information behaviour. Information Research, 9(1).

Heinström, J. (2005). Fast surfing, broad scanning and deep diving - The influence of personality and study approach on students' information-seeking behavior. Journal of Documentation, 61(2), 228-247. https://doi.org/10.1108/00220410510585205.

Heinström, J., Sormunen, E., \& Kaunisto-Laine, S. (2014). Spanning information behaviour across the stages of a learning task - where do personality and approach to studying matter? Journal of Documentation, 70(6), 1-23.

Howard, P.J., \& Howard, J.M. (1995). The Big Five quickstart: An introduction to the Five-Factor model of personality for human resource professionals. Charlotte, NC: Centre for Applied Cognitive Studies.

Huck, S.W. (2012). Reading Statistics and Research. $6^{\text {th }}$ ed. Boston, MA.

Ikoja-Odongo, R., \& Mostert, J. (2006). Information seeking behaviour: A conceptual framework. South African Journal of Libraries, 72(3), 145-158.

John, O., \& Srivastava, S. (1999). The Big Five trait taxonomy: History, measurement, and theoretical perspectives. In L. Pervin, \& O. John (Eds.), Handbook of personality: Theory and Research (pp.102-138). New York: Guilford Press.

Karatas, H. (2015). Correlation among academic procrastination, personality traits, and academic achievement. Anthropologist, 20(1, 2), 243-255.

Kim, K.S., Sin, S.C.J., \& Tsai, T.I. (2014). Individual differences in social media use for information seeking. The Journal of Academic Librarianship, 40(2), 171-178.

Komarraju, M., Karau, S.J., Schmeck, R.R., \& Avdic, A. (2011). The big five personality traits, learning styles, and academic achievement. Personality and Individual Differences, 51, 472-477. https://doi.org/10.1016/j.paid.2011.04.019. 
Koseoğlu, Y. (2016). To what extent can the big five and learning styles predict academic achievement. Journal of Education and Practice, 7(30), 43-51.

Kwon, N. \& Song, H. (2011). Personality traits, gender, and information competency among college students. Malaysian Journal of Library \& Information Science, 16(1), 87-107.

Lodi-Smith, J. \& Roberts, B.W. (2007). Social investment and personality: A metaanalysis of the relationship of personality traits to investment in work, family, religion, and volunteerism. Personality and Social Psychology Review, 11, 68-86.

Marchionini, G. (1997). Information Seeking in Electronic Environment, Cambridge University Press, UK.

Marchionini, G. (2006). Exploratory search: From finding to understanding. Communications of the ACM, 49(4), 41-46.

McCrae, R.R., \& Costa, P.T.Jr. (1988). Age, personality, and the spontaneous selfconcept. Journal of Gerontology, 43(6), 177-185.

McGeown, S.P., Putwain, D., Simpson, E.G., Boffey, E., Markham, J., \& Vince, A. (2014). Predictors of adolescents' academic motivation: Personality, self-efficacy and adolescents' characteristics. Learning and Individual Differences, 32, 278-286. https://doi.org/ 10.1016/j.lindif.2014.03.022.

Moore, C.L. (2016). A study of social media and its influence on teen information seeking behaviors, The Serials Librarian, 71(2), 138-145.

Nadzir, M., Wahab, A.\& Othman, N. (2015). Undergraduates' needs and seeking behaviour: A preliminary study. Journal of Educational and Vocational Research, 6(2).

Nadzir, M.M., \& Salim, J. (2013). Information seeking behavior factors: A measurement model. Paper presented at The $3^{\text {rd }}$ International Conference on Research and Innovation in Information Systems, November (pp.168-173). Selangor: Malaysia.

Nyarko, K., Kugbey, N., \& Amissah, C.M. (2016). The influence of the big five personality and motivation on academic achievement among university students in Ghana. British Journal of Education, Society \& Behavioural Science, 13(2), 1-7. https://doi.org/ 10.9734/BJESBS/2016/19618.

Ozowa, V., \& Aba, J.I. (2017). Perceived effect of personality traits on information seeking behaviour of postgraduate students in Universities in Benue State, Nigeria. Library Philosophy and Practice (e-journal).

Poropat, A.E. (2009). A meta-analysis of the Five-Factor model of personality and academic performance. Psychological Bulletin, 135(2), 322-338.

Rammstedt, B., \& John, O.P. (2007). Measuring personality in one minute or less: A 10item short version of the Big Five Inventory in English and German. Journal of Research in Personality, 41, 203-212. https://doi.org/10.1016/j.jrp.2006.02.001.

Rimfeld, K., Kovas, Y., Dale, P.S., \& Plomin, R. (2016). True grit and genetics: predicting academic achievement from personality. Journal of Personality and Social Psychology, 111(5), 780-789. http://dx.doi.org/10.1037/pspp0000089. 
Schmidt, T. \& Wolff, C. (2016). Personality and information behavior in web search. Association for Information Science and Technology, 53(1), 1-6.

Smith, J.K., Given, L.M., Julien, H., Ouellette, D., \& DeLong, K. (2013). Information literacy proficiency: Assessing the gap in high school students' readiness for undergraduate academic work. Library \& Information Science Research, 35, 88-96.

Song, H., \& Kwon, N. (2012). The relationship between personality traits and information competency in Korean and American students. Social Behavior and Personality, 40(1), 1153-1162. https://doi.org/10.2224/sbp.2012.40.7.1153.

Suldo, S.M., Minch, D.R., \& Hearon, B.V. (2014). Adolescent life satisfaction and personality characteristics: Investigating relationships using a Five Factor model. Journal of Happiness Studies, 16(4), 965-983.

Tidwell, M. \& Sias, P. (2005). Personality and information seeking: Understanding how traits influence information-seeking behaviors. Journal of Business Communication, 42(1), 51-77. https://doi.org/10.1177/0021943604272028.

Timmers, C.F., \& Glas, C.A.W. (2010). Developing scales for information-seeking behavior. Journal of Documentation, 66(1), 46-69.

Volodina, A., Lindner, C., \& Retelsdorf, J. (2019). Personality traits and basic psychological need satisfaction: Their relationship to apprentices' life satisfaction and their satisfaction with vocational education and training. International Journal of Educational Research, 93, 197-209. https://doi.org/10.1016/j.ijer.2018.11.003.

Wilson, T.D. (1981). On user studies and information needs. Journal of Documentation, 37, 3-15.

Wilson, T.D. (2000). Human information behavior. Information Science Research, 3(2), 49-55.1.

Winocur, E., Uziel, N., Lisha, T., Goldsmith, C. \& Eli, I. (2010). Self-reported Bruxism - associations with perceived stress, motivation for control, dental anxiety and gagging. Journal of Oral Rehabilitation, 38, 3-11. https://doi.org/10.1111/j.13652842.2010.02118.x.

Yamane, T. (1973). Statistics: An Introductory Analysis, $3^{\text {rd }}$ ed. New York: Harper and Row.

Zhitomirsky-Geffet, M., \& Blau, M. (2017). Cross-generational analysis of information seeking behavior of smartphone users. Aslib Journal of Information Management, 69(6), 721-739. https://doi.org/10.1108/AJIM-04-2017-0083.

Zhu, Y., Chen, L., Chen, H., \& Chern, C. (2011). How does internet information seeking help academic performance? - The moderating and mediating roles of academic selfefficacy. Computers \& Education, 57, 2476-2484. 